\title{
Research on Inventory Path Optimization of VMI Large Logistics Enterprises Based on Ant Colony Algorithm
}

Yaoyan Wang ( $\nabla$ yywangzjen@163.com )

Yiwu Industrial and Commercial College

\section{Research Article}

Keywords: VMI, ant colony algorithm, logistics enterprises, inventory path optimization

Posted Date: April 1st, 2021

DOl: https://doi.org/10.21203/rs.3.rs-371594/v1

License: (c) (1) This work is licensed under a Creative Commons Attribution 4.0 International License.

Read Full License 


\title{
Research on Inventory Path Optimization of VMI Large Logistics Enterprises Based on
}

\author{
Ant Colony Algorithm \\ Yaoyan Wang* \\ Yiwu Industrial \& Commercial College, Yiwu City, Zhejiang Province, China.322000 \\ *E.mail: yywangzjcn@163.com
}

\begin{abstract}
Based on the idea of vendor management (VMI) inventory, this paper focuses on the integration and optimization of transportation and inventory control in large-scale logistics system, so as to minimize the total cost of the logistics system. Aiming at the inventory path optimization of VMI large logistics enterprises, based on ant colony algorithm, an improved ant colony algorithm, namely ant colony system algorithm, is designed to solve the model. The algorithm model combines deterministic selection and random selection to obtain a comprehensive probability, and combines local and global pheromone updating. In this paper, we study a twolevel supply chain system with multiple customers from one supplier and inventory routing problem. According to the characteristics of inventory routing problem, a single cycle inventory path optimization model with time window constraint based on stochastic demand is established. The goal is to minimize the total system cost, including inventory cost of downstream customers, system transportation cost and penalty cost for not meeting the time window. According to the characteristics of the model, the ant colony algorithm is selected as the optimization method, and the improved ant colony algorithm is designed to solve the example, and the feasibility of the algorithm and model is verified.
\end{abstract}

Keywords: VMI; ant colony algorithm; logistics enterprises; inventory path optimization

\section{Introduction}

With the development of economy, the expansion of globalization and the aggravation of market competition, enterprises whose ultimate goal is to improve customer satisfaction are in a more complex market environment, and the scope of competition among enterprises is becoming larger and larger [1]. From the perspective of simple products, the competition between enterprises turns to the competition among supply chains. In today's increasingly severe market competition environment, enterprises must have a good insight into the market demand, and then make an effective and rapid response [2-3]. While improving their core competitiveness, they should pay more attention to the strategic cooperation with other cooperative enterprises in the whole supply chain. Different enterprises in the same supply chain can share resources, strengthen cooperation, make decisions and jointly develop the market. The Vendor Managed Inventory (VMI) based on the strategic thought of "horizontal integration" of supply chain management is developed from the systematic idea, which avoids the disadvantages of the traditional inventory management mode of enterprises that are independent and uncoordinated [4-6]. But from the overall point of view, the centralized management of inventory can make the relationship between enterprises in the supply chain closer, the operation more coordinated, enhance the enterprise's sensitivity and response to the market, and then improve their competitiveness.

Inventory control management and distribution path optimization are two important links to be solved in the system. However, there is a phenomenon of reverse benefit between inventory and distribution. If largescale distribution is adopted for the demander, it will inevitably reduce the number of transportation and increase the inventory cost of the demander while reducing the distribution cost. If the demand side adopts the small batch distribution mode, it will inevitably lead to the increase of distribution times, and then the distribution cost will increase, and the inventory cost of the demander will be reduced [7]. Therefore, it is necessary to jointly optimize the inventory control and distribution, optimize the whole system, determine the inventory control strategy and distribution path scheme, so as to balance the benefits of inventory and distribution.

The ant colony system algorithm was proposed by Dorigo in 1997 [8]. It is one of the most successful ant colony algorithms, which is widely used to solve combinatorial optimization problems. The key point of ant colony system algorithm is to update the local information and global information of the algorithm respectively, and use the combination of the two methods to solve the model [9]. Local pheromone updating refers to the pheromone concentration on the path adjusted by the local pheromone when $\mathrm{Ma} \mathrm{Nu}$ is looking for the ideal path; the global pheromone updating means that all ants will adjust the pheromone concentration on the optimal path found in the search process after all ants have completed the search. In this paper, the inventory routing problem of VMI large-scale logistics enterprises is simplified as a vehicle routing optimization problem with soft time windows and inventory constraints. In view of the design principles and characteristics of ant colony 
algorithm, it is applied to the inventory path optimization of VMI large-scale logistics enterprises based on ant colony algorithm with soft time window and inventory constraints.

\section{Construction of inventory path joint optimization model under VMI mode}

\subsection{Overview of VMI}

Supply chain refers to the management and control of information flow, logistics and capital flow around the core enterprises. It is a structural model composed of raw material suppliers, producers, distributors and final customers in the process of product production and circulation [10-11]. The mode presents the structural characteristics of network chain. Supply chain management embodies the idea of "horizontal integration". It carries out logistics activities from a global perspective, and emphasizes the cooperation and mutual exchange between the upper and lower enterprises in the supply chain, so as to improve the efficiency of the whole supply chain system. The goal of supply chain management is to find the best balance among the objectives of minimizing total cost, optimizing customer service, minimizing total inventory, minimizing total cycle time and optimizing logistics quality, so as to maximize the performance of supply chain. The network structure of supply chain is shown in Figure 1:

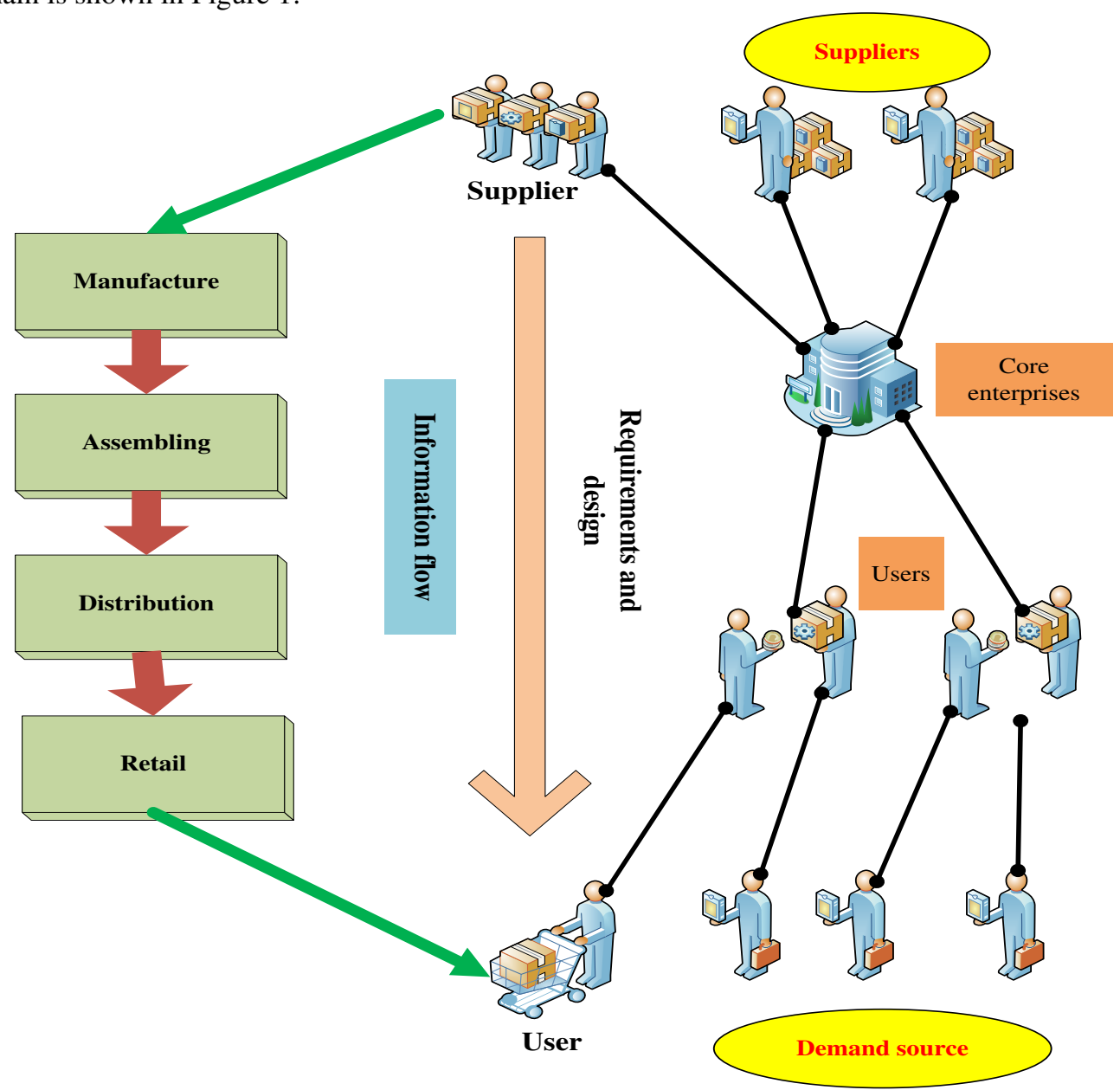

Figure 1. Network structure of supply chain

Supplier managed inventory (VMI) is the management and control of the inventory of downstream customers by suppliers and other upstream enterprises based on their downstream customers' production, operation and inventory information. In order to avoid the disadvantages of the traditional inventory management mode in the supply chain, each enterprise does its own business and does not cooperate closely [12]. It manages the inventory from the perspective of global optimization, which makes the relationship between the enterprises in the supply chain closer and more coordinated, enhances the enterprise's sensitivity and responsiveness to the market, and then improves its competitiveness.

The idea of VMI emphasizes the cooperation and intercommunication between enterprises in the supply chain. On the one hand, the enterprises in the supply chain need to realize information sharing. The smooth information in the supply chain ensures the coordinated operation of the supply chain. After the suppliers understand the information of customers, they can arrange and organize goods distribution and inventory 
management [13]. On the other hand, the supplier belongs to the decision-maker in the supply chain, and completely controls the inventory of the downstream customers in the supply chain until the goods are sold out. The implementation of VMI strategy can effectively manage the inventory in the supply chain, improve the stability of the supply chain, avoid the impact of demand amplification effect, and ensure the accuracy and timeliness of information transmission.

VMI is a demand-oriented inventory management strategy. In the supply chain system, the supplier is the decision-maker, and the supplier must make correct and reasonable decisions to ensure the good operation of the supply chain. Before organizing logistics activities, suppliers must accurately predict the demand of downstream customers, then arrange distribution and make a reasonable replenishment and distribution plan. VMI system is mainly composed of demand forecast and replenishment distribution, as shown in Figure 2:

\section{Inventory \\ information}

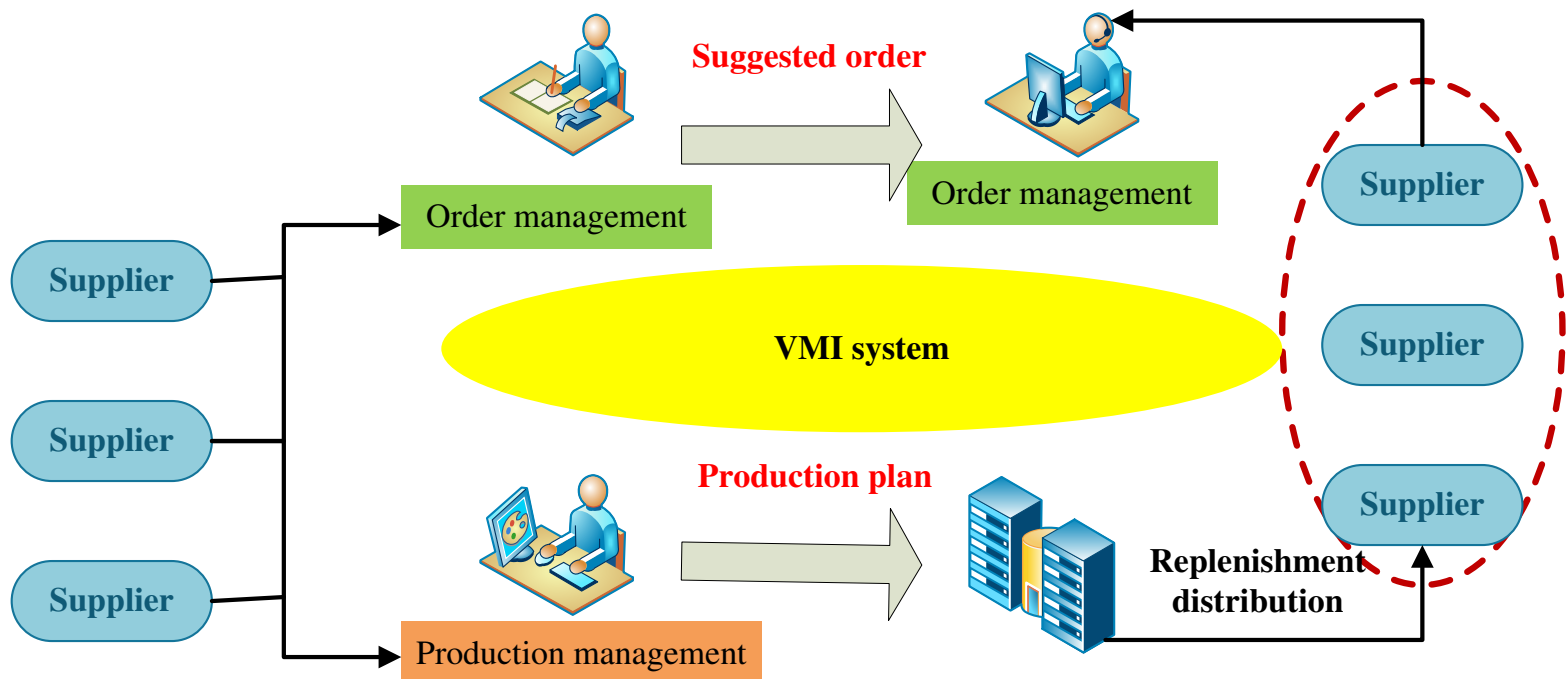

Replenishment distribution

Figure 2. Composition of VMI system

(1) Demand forecasting module

When implementing the strategy, the demand forecast is the guarantee for the supplier to make the correct inventory replenishment plan, and the accurate demand forecast can determine the time and quantity of goods distribution. Demand forecasting needs the transparency of information in the supply chain system. Customers' sales data and inventory data are shared in the supply chain system. After the suppliers master the customer's real-time data, they can refine the data they need, and then predict the customer's demand to determine the production plan and replenishment and distribution plan.

(2) Replenishment and distribution module

Replenishment and distribution service is carried out after the demand forecast. The purpose is to reduce the inventory level as much as possible, improve the customer satisfaction, reduce the inventory cost and distribution cost, and improve the efficiency of the supply chain. According to the demand forecast data, order data, customer inventory data and other data, the supplier determines the customer, replenishment time and replenishment quantity, arranges distribution service, and determines the production plan according to the actual inventory level. According to the transportation capacity, an efficient distribution scheme is formulated to minimize the inventory cost and distribution cost, that is, to maximize the economic benefits of the supply chain system.

\subsection{Inventory cost analysis}

Inventory cost refers to the cost generated to ensure the operation of the inventory system. The inventory cost involved in the operation of the inventory system is the main index to evaluate the advantages and disadvantages of the inventory control strategy. Generally speaking, inventory cost mainly consists of order cost, inventory holding cost and shortage cost [14].

(1) Order cost

Order cost refers to the cost of goods ordered by customers, that is, the sum of all costs in the process of replenishment. The cost has nothing to do with the quantity of goods ordered, only related to the number of orders. In the system studied in this paper, in order to simplify the model, this part of the cost is not considered.

(2) Inventory holding cost 
Inventory holding cost refers to the cost of holding or storing goods, which is directly proportional to the average amount of inventory held in a certain period of time. Statistics show that the annual storage cost of general goods is as high as its value. It mainly includes capital cost, storage space cost, inventory service cost and inventory risk cost.

1) Capital cost: refers to the funds occupied due to inventory, which can be used for other investments. Capital cost is usually regarded as the opportunity cost of an enterprise, which is the most important part of inventory holding cost.

2) Storage space cost: refers to the cost of storage space occupied by inventory, which includes warehouse management cost and facility maintenance cost.

3) Inventory service cost: including taxes and insurance of materials. Among them, the tax is calculated according to the amount of goods in stock, the insurance premium is caused by keeping inventory, and the tax and insurance are related to the type and value of the goods in stock.

4) Inventory risk cost: refers to the storage loss, obsolescence and falling price loss of materials. Materials in the warehouse, in addition to corruption, deterioration, theft and other losses, but also due to the development of technology, the emergence of new products, so that the value of goods in stock is greatly reduced.

(3) Out of stock cost

The shortage cost is used to measure the loss caused by shortage. The upper level supplier can not meet the needs of the lower level customers, which results in the economic loss of the whole system. The shortage cost includes lost sales cost and customer waiting cost. The loss of sales cost is caused by the cancellation of purchase requirements by the customer; the customer waiting cost is when the customer can accept the shortage and is willing to delay the delivery of the upper level supplier, which also brings the risk of losing the future sales opportunities.

In the traditional inventory theory, the decision that must be made is how much goods should be ordered. The correct order quantity should make the related cost reach the best balance, the total cost should be the minimum, and the replenishment quantity should be determined to balance the related cost. Similar to the traditional inventory theory, the inventory cost relationship based on VMI is shown in Figure 3:

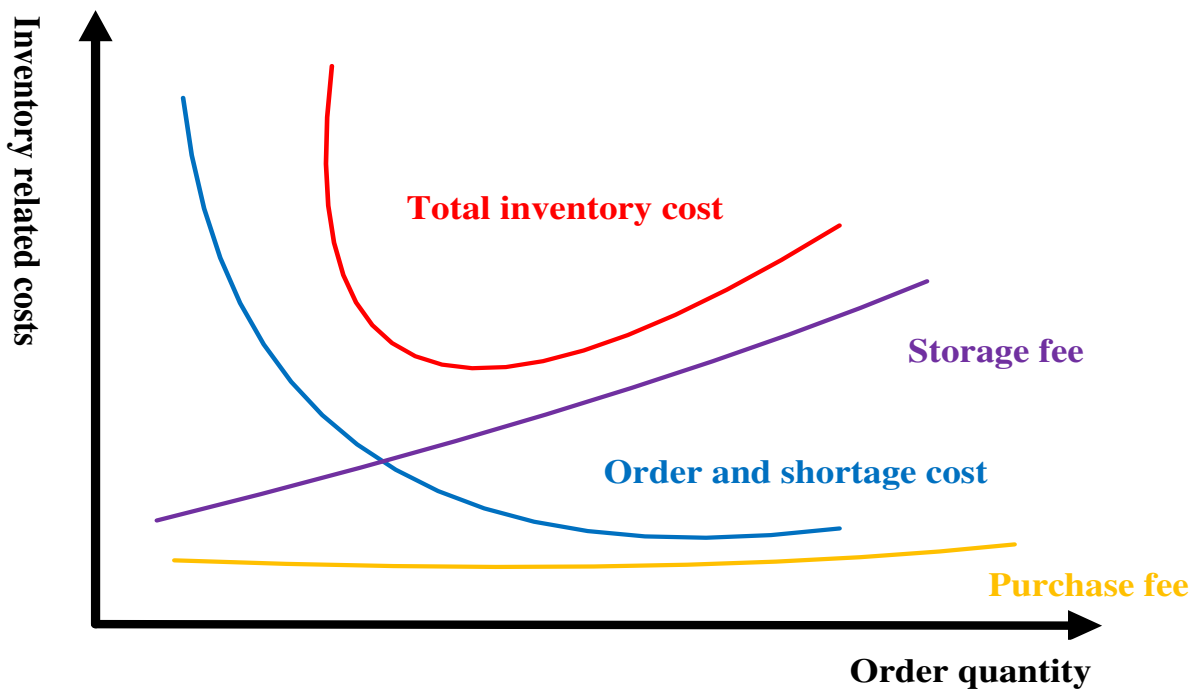

Figure 3. Analysis of system inventory cost based on VMI

\subsection{Establishment of optimization model}

In the transportation network, the supplier does not directly serve the customers, but delivers the goods to the distribution center, and then the distribution center provides distribution services to the customers. The service mode adopted is one to many, and one car may serve one or more customers. The transportation network is suitable for the situation that the demand of customers is small, that is, small batch transportation. The establishment of distribution center reduces the distance between the demand point and the place where the goods are located, thus reducing the operation and management cost of the supplier, while the small batch transportation reduces the transportation cost. The planning based on the transportation network is complex and needs to be built on the basis of high informatization. The transport network structure is shown in Figure 4: 


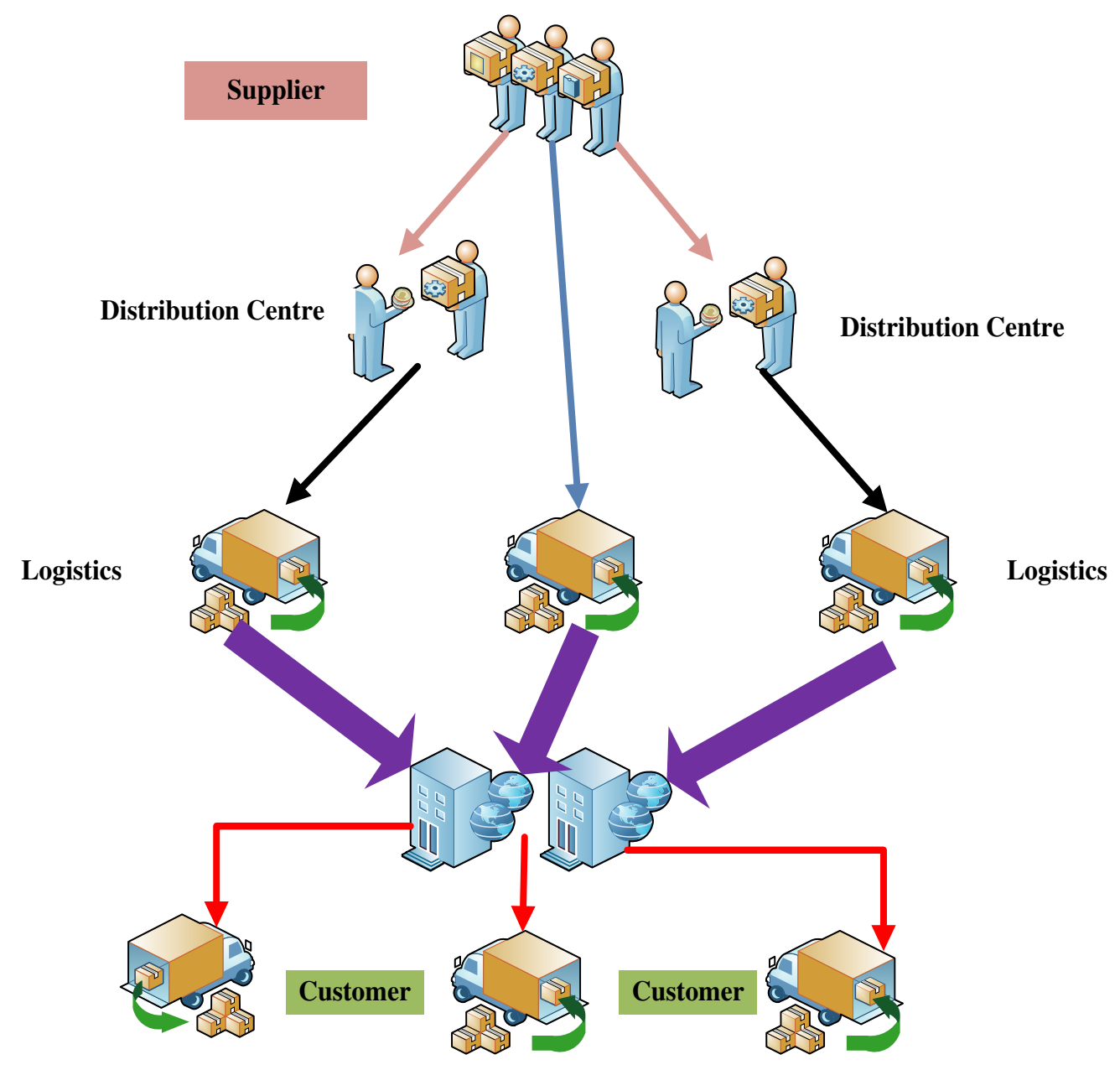

Figure 4. Traveling salesman transport map with distribution center

According to the different needs of customers, it can be divided into two time windows: hard time window and soft time window. For the vehicle routing problem with hard time window, the vehicle must arrive at the customer within the required time window and provide service, otherwise the distribution task will fail; the vehicle routing problem with soft time window requires the vehicle to meet the constraints of the time window as far as possible. If the service fails to meet the time window, the customer can still accept it, but there will be a certain penalty cost. Two kinds of costs should be considered in the vehicle routing problem with hybrid time window constraints: one is the vehicle travel cost (related to the transportation distance); the other is the penalty cost caused by the failure to meet the time window constraint. Generally speaking, the amount of penalty fee is determined by negotiation between supplier and customer. However, the common characteristic of penalty cost is that the more vehicle arrival time deviates from the constraint time window, the higher the penalty cost.

In this paper, we assume that the penalty cost increases linearly, $\mathrm{P}$ is the penalty coefficient due to the early arrival of the vehicle, and the penalty cost of the vehicle arriving at the customer at time $t$ is:

$$
Q=Q_{\max }\left\{\left(a_{i}-x_{i}\right), 0\right\}
$$

Distribution is one of the important links in the supply chain system, and the distribution cost is one of the items with the largest proportion in the total cost of the system. Therefore, the good operation of the supply chain must be based on a good distribution scheme, so as to improve the competitiveness of enterprises. In the VMI environment, it changes the passive mode that suppliers arrange delivery and replenishment according to the orders of lower level customers in the supply chain. Instead, the initiative is in the hands of suppliers, and the suppliers grasp the needs of lower level customers, and then distribute goods.

Distribution cost refers to the expenses generated in the process of goods distribution. The distribution process includes: preparing goods, sorting goods and transporting goods. The distribution cost involves many aspects, such as fuel cost, labor cost, management cost, etc. These costs can be artificially divided into variable costs with the volume of transportation and fixed costs that do not change with the volume of transportation. 
Fixed cost includes maintenance and management cost, equipment and facilities cost. In this paper, the starting cost $r_{0}$ of unit delivery vehicle is taken as the fixed distribution cost. Variable cost is the transportation cost of line vehicles, and the unit transportation cost $r_{1}$ is regarded as the variable cost in this paper. Therefore, the distribution cost of the system is as follows:

$$
S_{2}=t_{1} \sum_{i}^{m} \sum_{j}^{n} \sum_{k}^{t} d_{i j} x_{i j k}+r_{0} s
$$

In this paper, through the joint optimization of inventory and routing, under the constraints of time window, we seek the inventory strategy and distribution scheme with the minimum single cycle total cost (including the inventory cost at the customer and the distribution cost generated in the distribution process). The total system cost in the planning period is as follows:

$$
S T=t_{1} \sum_{i}^{m} \sum_{j}^{n} \sum_{k}^{t} d_{i j} x_{i j k}+t_{0} s+\sum_{i=1}^{m}\left[m_{0} \int_{0}^{P_{1}}\left(P_{1}-x\right) d_{G(x)}+m_{1} \int_{P_{1}}^{\infty}\left(P_{1}-x\right) d_{G(x)}\right]+q \sum_{i=1}^{s} \max \left[a_{i}-s_{i}, 0\right]
$$

Therefore, the objective of the joint inventory path optimization problem based on stochastic demand is to minimize the total system cost, and the objective function and constraints are transformed as follows:

$$
\min S T=t_{1} \sum_{i}^{m} \sum_{j}^{n} \sum_{k}^{t} d_{i j} x_{i j k}+t_{0} s+\sum_{t=1}^{m}\left[m_{0} \int_{0}^{P_{1}}\left(P_{1}-x\right) d_{G(x)}+m_{1} \int_{P_{1}}^{\infty}\left(P_{1}-x\right) d_{G(x)}\right]+q \sum_{i=1}^{s} \max \left[a_{i}-s_{i}, 0\right]
$$

The formula expresses the solution goal, that is, the minimum system cost under the given constraint conditions, including: the total transportation cost, the system inventory cost and the penalty cost caused by not meeting the time window constraint.

\section{Research and design of VMI inventory routing algorithm based on ant colony algorithm}

\subsection{Principle of ant colony algorithm}

Ant colony algorithm (ACO) is an artificial intelligence algorithm proposed by Dorigo in 1992 to observe the process of ants searching for food and simulate their foraging strategies and behaviors. The principle of ant colony algorithm is that the ants in the ant colony go foraging, and each ant will release pheromone as a marker on the path it passes, and this behavior will also affect its peers, and the concentration of pheromone will affect its partner selection. Other ants will search along the path with higher pheromone concentration, and finally find the optimal path. The algorithm also simulates ants in the ant colony, and uses functions to express pheromone release, concentration change, optimization and other behaviors. The behavior of ant colony is a kind of spontaneous positive feedback behavior of swarm intelligence learning, with fast convergence speed, strong writing ability, reasonable distribution and robustness. The research elements of ant colony algorithm are as follows:

(1) Artificial ants. As the driving factor of ant colony algorithm, artificial ant has great influence on the whole algorithm. It is assumed that the size of ant colony is determined by the number of artificial ants, and it is set to $\mathrm{m}$. The results show that the size of $\mathrm{M}$ affects the searching effect, searching speed and convergence efficiency of dispersal. In short, if $\mathrm{M}$ is too large, the advantage is that the ant search range will be increased, and the global optimal solution can be obtained more easily. The disadvantage is that the number of ant colony is too large, the search efficiency of the algorithm is reduced, and the convergence direction cannot be controlled, resulting in poor convergence of the algorithm. On the contrary, if $\mathrm{M}$ is too small, the advantage is that the operation efficiency is greatly improved and the result is easy to be obtained. The disadvantage is that the solution set is less and it is easy to fall into the local optimal solution.

(2) Pheromone. Pheromone is an important part of ant colony algorithm, which is equivalent to the driving factor. It is the link between ant colony and individual. Ants can communicate with other ants and choose path through information. Ants can judge the advantages and disadvantages of path by pheromone. In general ant colony algorithm, pheromones are stored in the form of a two-dimensional matrix, which changes with the iteration of the algorithm.

(3) Path selection strategy. In the traditional ant colony algorithm, the strategy of path selection is determined according to the information content and pheromone concentration of the current path. Generally, the value of the product of the two factors on the current path is divided by the proportion of the sum of these products on all paths, and the higher the selection probability is. With the increase and development of algorithms, path selection strategy began to combine with other algorithms to learn from each other. 
(4) Pheromone update. The pheromone update strategy of current path is called local pheromone updating strategy, and pheromone updating strategy of optimal path and worst path after global traversal is called global pheromone updating strategy. These two strategies are pheromone updating strategies in ant colony algorithm.

Ant colony algorithm is more common in vehicle routing optimization problem, but the problem in this paper can be simplified to solve vehicle routing optimization problem, the following assumptions can be made: Suppliers also exist in a certain area. A transport vehicle is dispatched from a designated supplier to visit each supplier in turn. It is stipulated that each supplier can only be visited once. After the visit, the vehicle will return to the starting point, and the ultimate goal is to plan the shortest route for completing the task.

In this problem, set the number of ants as $\mathrm{m}$, the number of suppliers as $\mathrm{N}$, the distance between supplier I and supplier $\mathbf{J}$, and the visibility parameter is expressed as, where, represents the tendency of supplier I to supplier $\mathrm{J}$, and $\mathrm{j}$ is the supplier to be visited. The pheromone content of the route between supplier I and supplier $\mathrm{J}$ is expressed as follows: the pheromone quantity generated by ant $\mathrm{K}$ on path ij is, and the probability of ant $\mathrm{K}$ transferring from supplier I to city $\mathrm{J}$ is expressed by transfer probability. In the running process of the algorithm, the walking path of a single ant is a feasible solution of the algorithm, and the ant influences the next step behavior through the pheromone concentration and heuristic information on the walking path. This influence is called transition probability.

\subsection{Design of ant colony system algorithm}

(1) State transition rules

First of all, all ants are randomly placed on the prepared atlas. When all ants have constructed the path, they will store pheromones on the path they have built. When the new leech arrives at the node of the path, it will judge which path to choose according to the number of pheromones left on the path by the ants that have already passed the path. If the pheromone concentration on a certain path is low, the new ants arrive at the node of the path to select the path, and the probability of choosing the path is small. When the traditional ant colony algorithm constructs the solution, its evolution speed is very slow, and even stagnation phenomenon occurs. The main reason for this is that it uses random selection strategy to solve the problem. In order to make this situation no longer happen, it is necessary to improve the ant colony algorithm, dynamically adjust the construction probability while constructing the path, and use the combination of deterministic selection and random selection to construct the path. The rules for ants to decide the next node to visit are as follows:

$$
P=\left\{\begin{array}{l}
\max \left\{B t_{i, j}\right\}, \text { if } s \leq s_{0} \\
Q_{i, j}, \quad \text { if } s>s_{0}
\end{array}\right.
$$

In the expression of equation, $s_{0}$ is a pre-defined probability parameter in the $(0,1)$ interval, and $\mathrm{P}$ is a random number in the $(0,1)$ interval. If $s$ is less than or equal to $s_{0}$, the selected arc should have the highest attraction. On the contrary, if $s$ is greater than $s_{0}$, the selected arc is determined according to the given construction probability:

$$
Q_{i, j}=\left\{\begin{array}{l}
B t_{i, j} / \sum_{k} B t_{i, k}, k \in \Theta \\
0
\end{array}\right.
$$

The expression of the above formula is called the pseudo-random probability selection rule, which determines the method of selecting the next node by the leech. Once the ant wants to make a choice, a random number will appear automatically in the interval $(0,1)$, judge the numerical range of the random number, and return to formula to determine the transition direction of the leech.

Finally, attij represents the attraction of the arc (I, J) to the female ant:

$$
B t_{i, j}=\left(\eta_{i, j}\right)^{\alpha}\left(\gamma_{i, j}\right)^{\beta}
$$

In this formula, it represents the expected degree between nodes, that is, if the distance between nodes is smaller, the probability of being selected by ants is greater. Where, is the parameter of the influence degree of pheromone on the arc, reflecting the importance of the amount of information remaining on the arc in the search process of ant colony, which is called information heuristic factor; is the parameter of desire degree of arc, reflecting the importance of the expected value on the arc, called expectation heuristic factor.

(2) Local pheromone update rules

After each artificial ant passes a path, it needs to update the pheromone of the path immediately. The update rules are shown in the following expression:

$$
\eta_{i, j}=(1-\lambda) \cdot \eta_{i, j}+\lambda \mathrm{g} \eta_{0}
$$


The Formula means that $\lambda$ is the pheromone volatilization ratio coefficient of ants in the $(0,1)$ interval, and $1-\lambda$ is the pheromone residue coefficient.

(3) Global pheromone update rules

Global pheromone updating is to update pheromones distributed on all paths on the basis of constructing the best path by all ants, and then form the current optimal path. Pheromones on other paths are automatically set to their current state. After global pheromone updating, all ants' states will be updated. In the next iteration, they will be in a better starting point, which can obtain a better solution. The specific update rules are as follows:

$$
\eta_{i, j}=(1-\lambda) \cdot \eta_{i, j}+\lambda / \Psi
$$

According to formula, when choosing a new starting point, ants will refer to the pheromone value and the weight of the arc to compare and select the best one. Of course, each node in the given graph set has been visited by ants more than or equal to one. In the established model, the number of vehicles and the carrying capacity of the fleet are limited, which can not guarantee that all retailers can be satisfied in a replenishment cycle. In view of this, the replenishment sequence of retailers can follow a sequence, but those nodes that need priority supply should advance their order. Obviously, the traditional ant colony algorithm can not meet this requirement because it only considers the transportation cost in the running process, ignoring the inventory holding cost and shortage cost in the system. Therefore, if the shortage cost and inventory holding cost of a node are higher, even if its transportation cost is lower than that of other nodes, the priority should be considered. To sum up, the update rules of arc selection mechanism can be expressed as follows:

$$
B t_{i, j}=\left(\eta_{i, j}\right)^{\alpha}\left(\gamma_{i, j}\right)^{\beta}\left(\varsigma_{J}\right)^{\gamma}\left(\psi_{J}\right)^{\delta}
$$

\subsection{Solving process of ant colony system algorithm to model}

Firstly, the distances between retailers and retailers and between retailers and suppliers are calculated according to the coordinate positions of retailers. Then, according to the demand of each retailer and the inventory at the beginning and the end of the period, the retailer decides whether to distribute to the retailer and the amount of distribution, and calculates the cost of stock out and the loss cost of shortage. Finally, matlab programming is used to load basic data and parameters, and ant colony system algorithm is used to obtain the distribution route and cost, so as to get the assembly of the system.

It is known that there are $n+1$ nodes in the IRP problem, which are independent of each other and have no connection with each other. For the convenience of research, the distribution center is defined as the first node, and the retailer corresponds to the remaining nodes respectively. Each ant must start from the first node and return to this node again after a circle of visits to form a path. All ants will do the same behavior, so there will be many different paths to visit all nodes (retailers)。When any ant starts from the distribution center and returns to the distribution center, the variable automatically increases with the return of the ant. As more ants return to the distribution center, the value of variable B becomes larger and larger. When it increases to N, the path construction is completed. The calculation process of the algorithm is to set the initial value of parameters and the termination rules of the program, and then dispatch a man-made leech from the first node to form a path corresponding to an initial total cost and initial solution. Each ant is successfully distributed, so each ant builds a path. With the successful construction of each ant losing the new path, the pheromone will be updated once. Before each generation, the number of program cycles needs to be reset. At the end of iteration, pheromone will be updated once, and the updated rules take the form of global update. At the same time, the best solution obtained by each iteration allows mutual communication until all solutions are centralized. At this time, the calculation stops. In the process of real operation, it may take a long time to reach the solution set. Therefore, a termination rule is set to reduce the operation time, that is, when the running algebra is equal to the parameter five set in the termination rule, the operation will stop.

\section{Experiment and analysis}

In order to verify the feasibility of the model and the algorithm, this paper takes a two-level supply chain distribution network system composed of one supplier and 15 retailers as the research object, and constructs a numerical example for analysis. The supplier implements VMI management for a certain product of retailer through information sharing. All retailers in the system are evenly distributed in a $(-50,50)$ coordinate plane. The coordinate positions of suppliers and retailers are shown in Figure 5. 


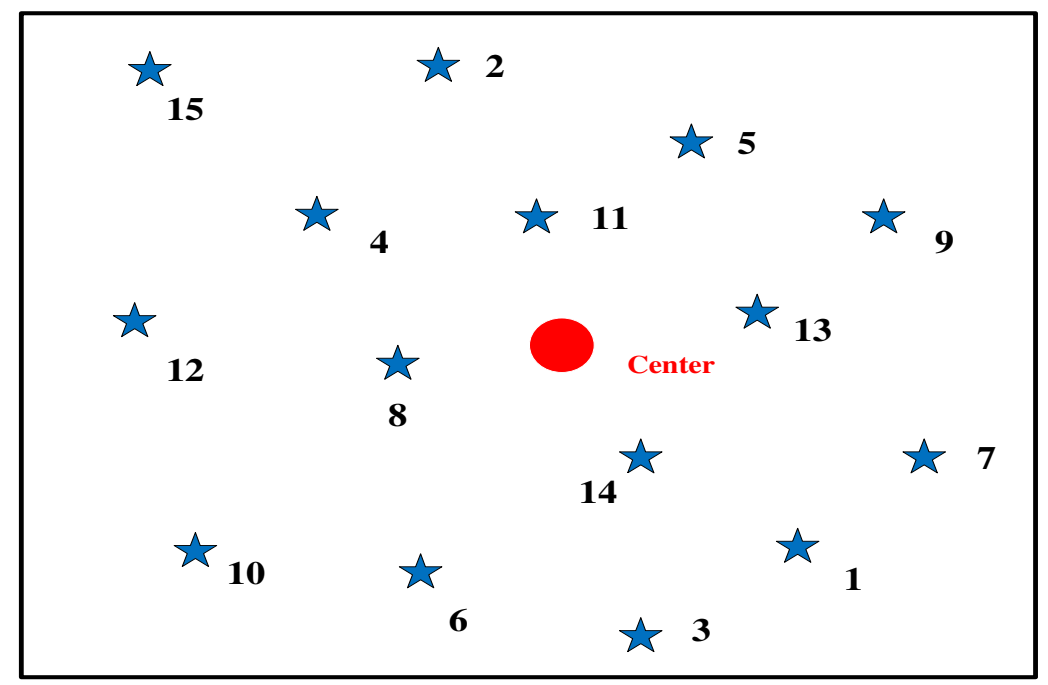

Figure 5. Coordinates of suppliers and retailers

If the two retailers and the generated location are divided into $\mathrm{x}$ and $\mathrm{y}$. The distance between two retailers is DXY, and D represents the distance between retailers and vehicles. In this paper, a low cycle inventory path optimization model based on stochastic demand and considering mixed time window constraints is constructed. The objective function is to minimize the total cost including system transportation cost, customer inventory cost and penalty cost for not meeting the time window. In this paper, the software program is used to solve the model. The iterative change of the system objective function is shown in Figure 6.

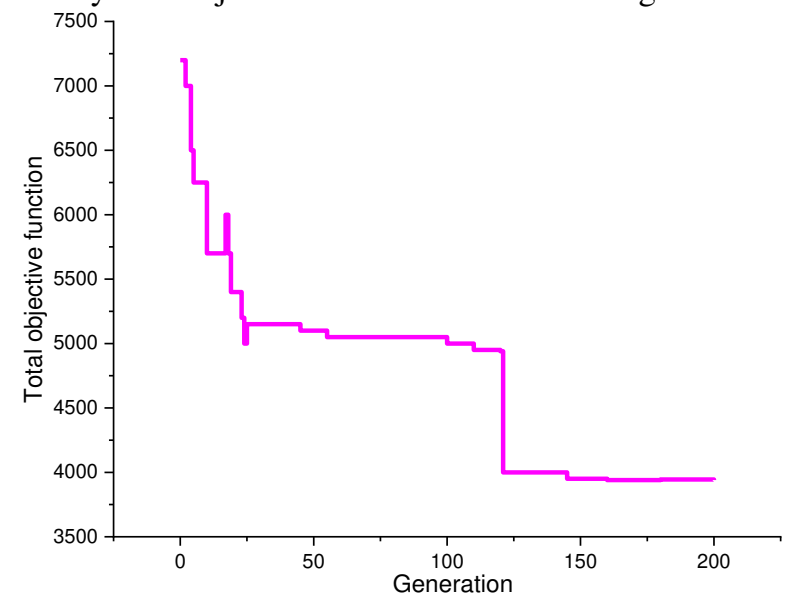

Figure 6. Iterative graph of system total objective function

The objective function of this paper is to minimize the total cost of the system, which includes the following three parts: total distribution cost, total inventory cost and time penalty cost. The system total distribution cost includes vehicle transportation cost and vehicle fixed cost. The iterative changes of vehicle transportation cost and vehicle fixed cost are shown in Figure 7 and Figure 8.

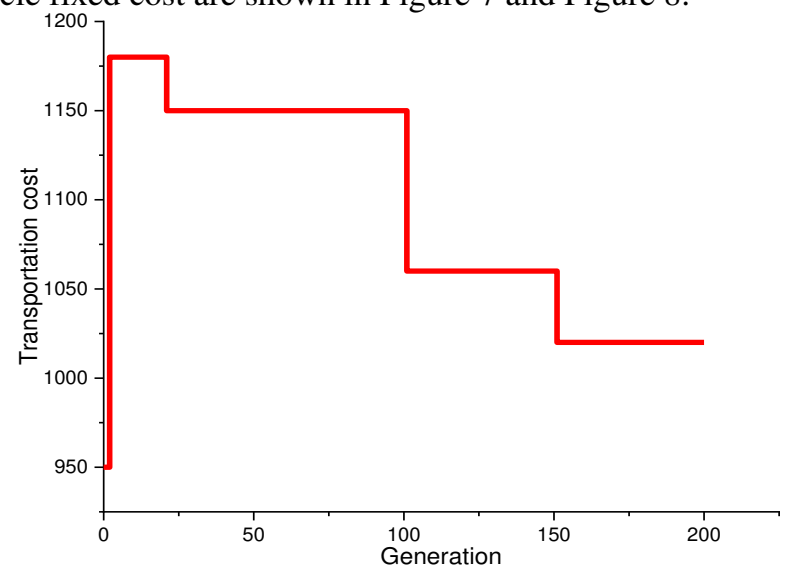


Figure 7. Transportation cost iteration chart

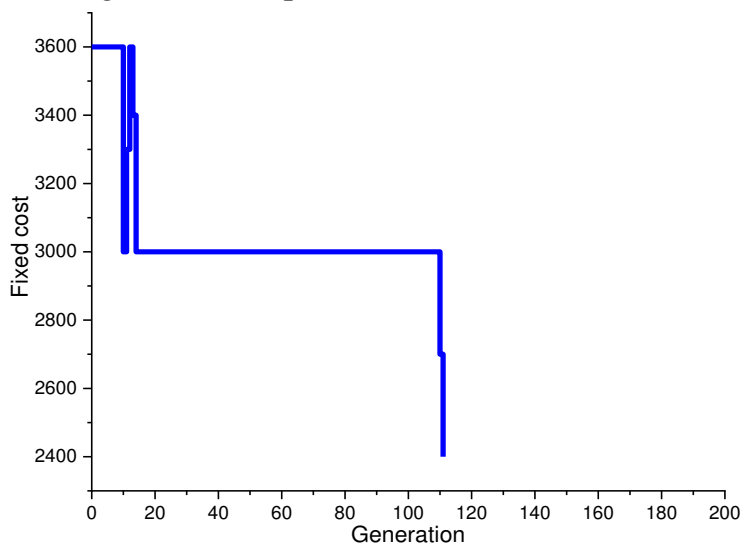

Figure 8. Fixed cost iteration chart

It can be seen from Figure 5-4 and Figure 5-5 that the vehicle transportation cost and vehicle fixed timber showed an unstable change from high to low before the 20th generation, and gradually decreased after the 20th generation. The vehicle transportation cost tends to be stable around 160 iterations to generations, which shows a good convergence effect; the fixed vehicle cost is related to the number of vehicles sent by the distribution center, and the iteration diagram starts to become a straight line around 115 generations, reaching a stable state, and achieves better optimization results.

The total inventory cost of the system includes the system inventory holding cost and system out of stock cost. This paper studies R-system, which only considers the inventory cost of customers. The iterative change of system inventory cost is shown in Figure 9:

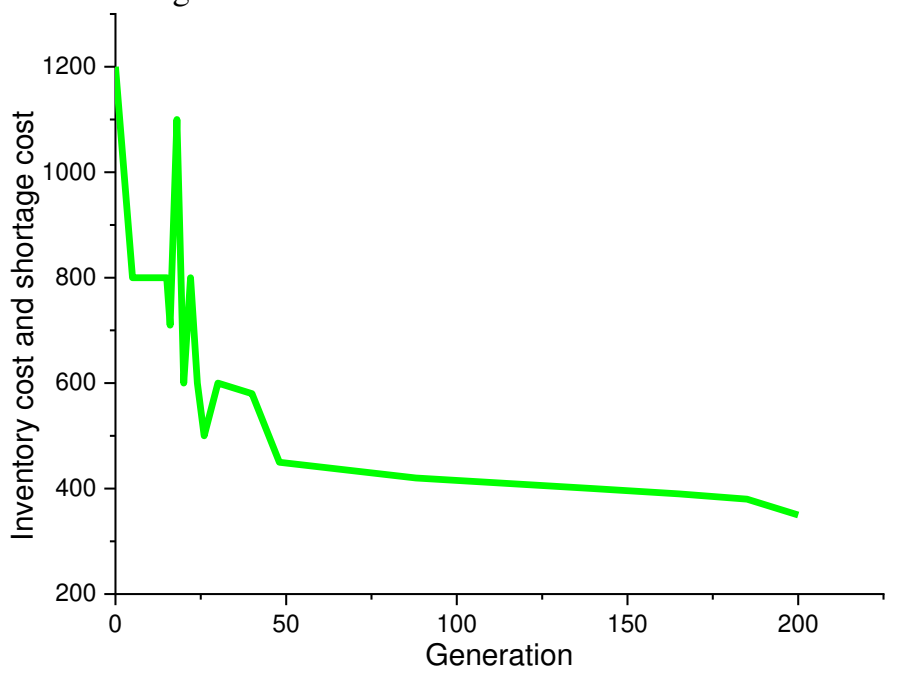

Figure 9. Iteration chart of inventory cost change

In this paper, we need to make a decision on the optimal distribution quantity of each customer and the vehicle routing problem. The optimal distribution quantity can be seen from the output results of the main program of genetic algorithm, as shown in Table 1.

Table 1. Customer's optimal delivery volume

\begin{tabular}{|c|c|c|c|c|c|c|c|c|c|c|c|c|c|c|c|}
\hline $\begin{array}{c}\text { Customer } \\
\text { number }\end{array}$ & 1 & 2 & 3 & 4 & 5 & 6 & 7 & 8 & 9 & 10 & 11 & 12 & 13 & 14 & 15 \\
\hline $\begin{array}{c}\text { Optimal } \\
\text { delivery } \\
\text { volume }\end{array}$ & 76 & 57 & 73 & 79 & 76 & 53 & 75 & 65 & 76 & 91 & 75 & 75 & 77 & 34 & 78 \\
\hline
\end{tabular}




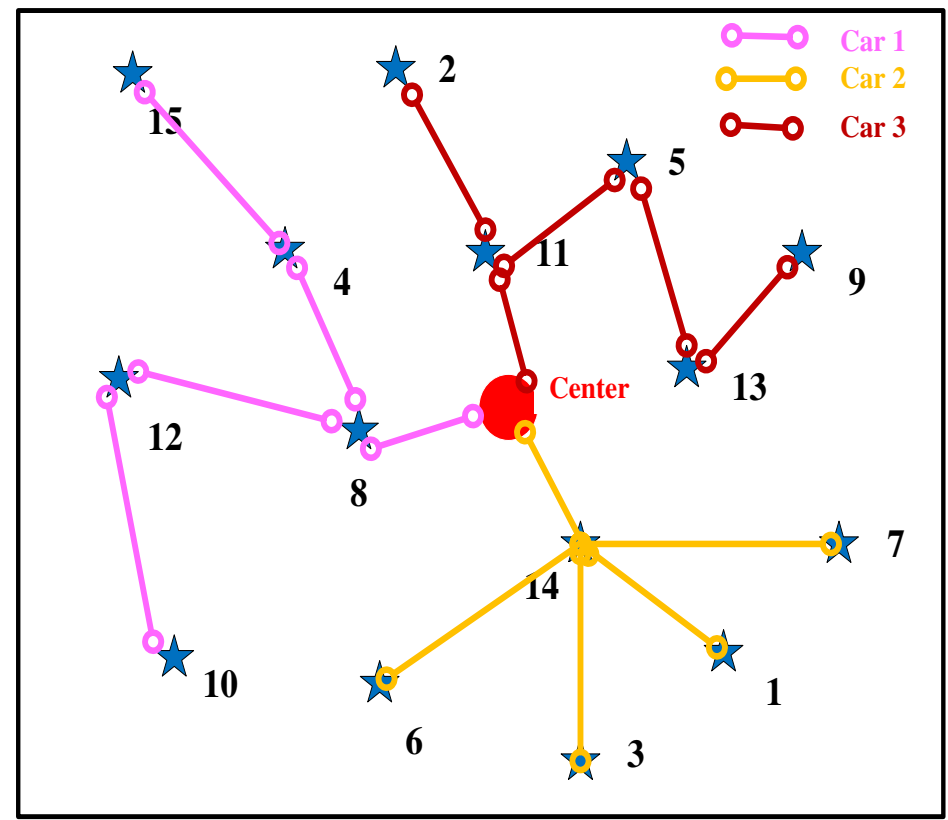

Figure 10. Vehicle route map

The vehicle path is shown in Figure 10. It can be seen from the figure that the distribution center sends four vehicles to carry out the distribution task. From the output results of ant colony algorithm, we can know the customers served by each vehicle, that is, the path of four vehicles. According to the output of the main program of the algorithm, after 200 iterations, the algorithm has got a good convergence effect and achieved the purpose of optimizing the total cost of the system, and the optimal cost of the system is about 4000 yuan. From the optimization results of the example, the improved ant colony algorithm designed in this paper is effective in solving the inventory path joint optimization model.

\section{Conclusion}

This paper mainly studies the inventory path optimization of VMI large-scale logistics enterprises based on ant colony algorithm, establishes a reasonable model, designs the algorithm to solve the model, and analyzes the results of calculation examples. Based on the analysis of the research and the understanding of the real life, this paper considers that the retailer is in a dominant position compared with the supplier in the VMI environment, and analyzes the game process of the retailer dominant. At the same time, this paper analyzes the cooperative game between the transportation party and the inventory party, and also analyzes the non cooperative game between the two sides. Based on the goal of maximizing benefit and minimizing cost, this paper not only improves the inventory control system, but also analyzes and plans the transportation route. In the VMI environment, the traditional transportation and distribution strategy is changed. The suppliers will take the initiative to adopt more effective solutions according to the effective feedback from downstream enterprises, instead of passively accepting orders for delivery. Both suppliers and retailers get benefits. Suppliers integrate resources, reduce costs, have efficient distribution efficiency and better serve users. For downstream enterprises, they not only meet their own needs, but also expand their interests. The implementation of VMI is based on the effective solution of inventory path optimization problem, which shows that in order to ensure the win-win situation of suppliers and their downstream enterprises.

\section{Compliance with Ethical Standards}

Conflicts of interest- No conflicts of interest.

Research involving traditional transportation and distribution strategy - Not applicable.

Informed consent- Not applicable.

\section{References}

[1] Yanwei D , Henggang L . Multi-Objective Optimization Model and Solution for Easily Broken Material Loading Based on Genetic Algorithms Under VMI[J]. Open Automation \& Control Systems Journal, 2015, 7(1):525-532.

[2] Kucuktezcan C F , Genc V M I . Preventive and corrective control applications in power systems via Big Bang-Big Crunch optimization[J]. International Journal of Electrical Power \& Energy Systems, 2015, 67(may):114-124. 
[3] Chen Z . Reprint of "Optimization of production inventory with pricing and promotion effort for a singlevendor multi-buyer system of perishable products"[J]. International Journal of Production Economics, 2019, 209(MAR.):285-301.

[4] Ratna Wati D A , Dzakiyullah N R, Saleh C, et al. Particle Swarm Optimization for Vendor Managed Inventory Control System of Multi Product Multi Constraints[J]. Advanced Science Letters, 2015, 21(10):32783282.

[5] Arora V, Chan F T S, Tiwari M K. An integrated approach for logistic and vendor managed inventory in supply chain[J]. expert Systems with Applications, 2010, 37(1): 39-44.

[6] Zhao W Y, Zhang B. Research on the Optimization of Inventory Routing Problem Based on VMI-TPL Mode[C]//Applied Mechanics and Materials. Trans Tech Publications Ltd, 2013, 409: 1089-1092.

[7] Harifi S, Khalilian M, Mohammadzadeh J, et al. Optimization in solving inventory control problem using nature inspired Emperor Penguins Colony algorithm[J]. Journal of Intelligent Manufacturing, 2020: 1-15.

[8] Liao S H, Hsieh C L, Lai P J. An evolutionary approach for multi-objective optimization of the integrated location-inventory distribution network problem in vendor-managed inventory[J]. Expert Systems with Applications, 2011, 38(6): 6768-6776.

[9] Teng L, Zhang Z, Li P, et al. Integrated Inventory-Transportation Problem in Vendor-Managed Inventory System[J]. IEEE Access, 2019, 7: 160324-160333.

[10] Dai Z, Luo Z. The Improvement Research of Ant Colony Algorithm In The Bullwhip Effect Application[M]//Logistics: The Emerging Frontiers of Transportation and Development in China. 2009: 36413647.

[11] Dasaklis T, Casino F. Improving vendor-managed inventory strategy based on Internet of Things (IoT) applications and blockchain technology[C]//2019 IEEE International Conference on Blockchain and Cryptocurrency (ICBC). IEEE, 2019: 50-55.

[12] Zachariassen F, De Haas H, Bürkland S. Vendor Managed Inventory: Why you need to talk to your supplier[J]. Journal of Industrial Engineering and Management, 2014, 7(4): 831-856.

[13] Guersola M, Steiner M T, Scarpin C. Customers scheduling and clustering as vendor managed inventory enablers[J]. International Journal of Logistics Systems and Management, 2019, 34(1): 56-74.

[14] Lin S, Kernighan B W. An effective heuristic algorithm for the traveling-salesman problem[J]. Operations research, 1973, 21(2): 498-516. 
Figures

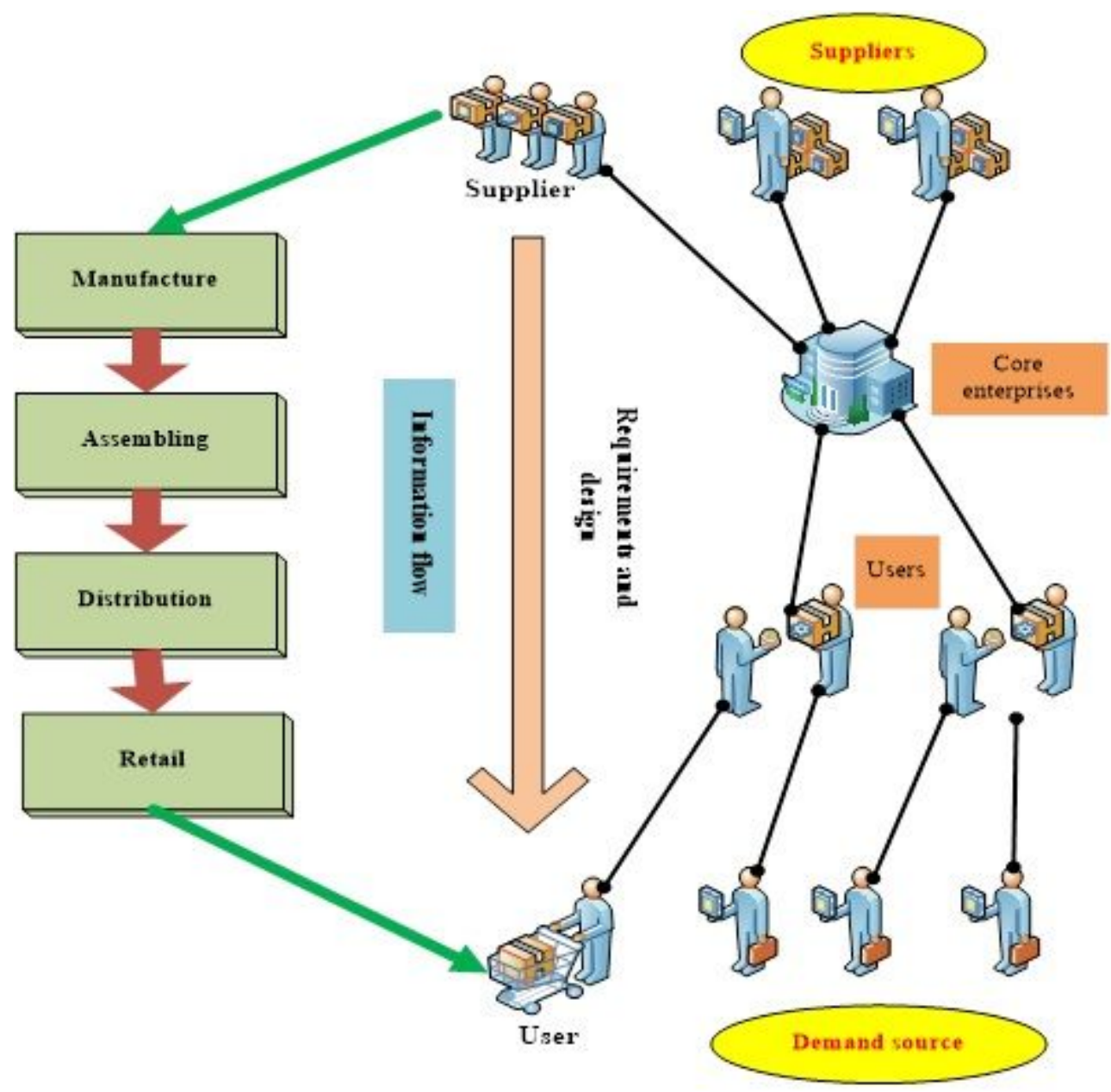

Figure 1

Network structure of supply chain

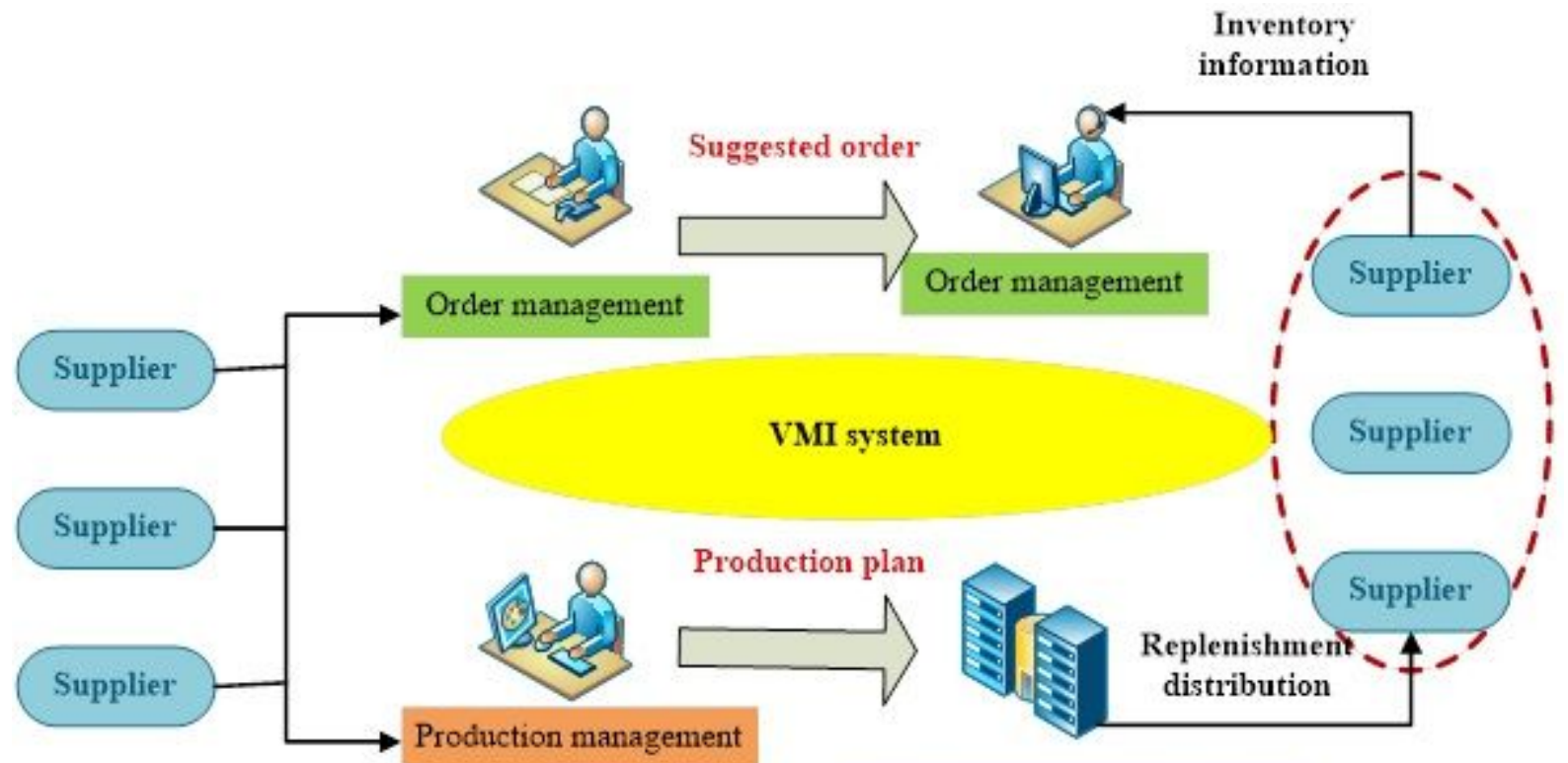

Replenishment distribution 
Figure 2

Composition of VMI system

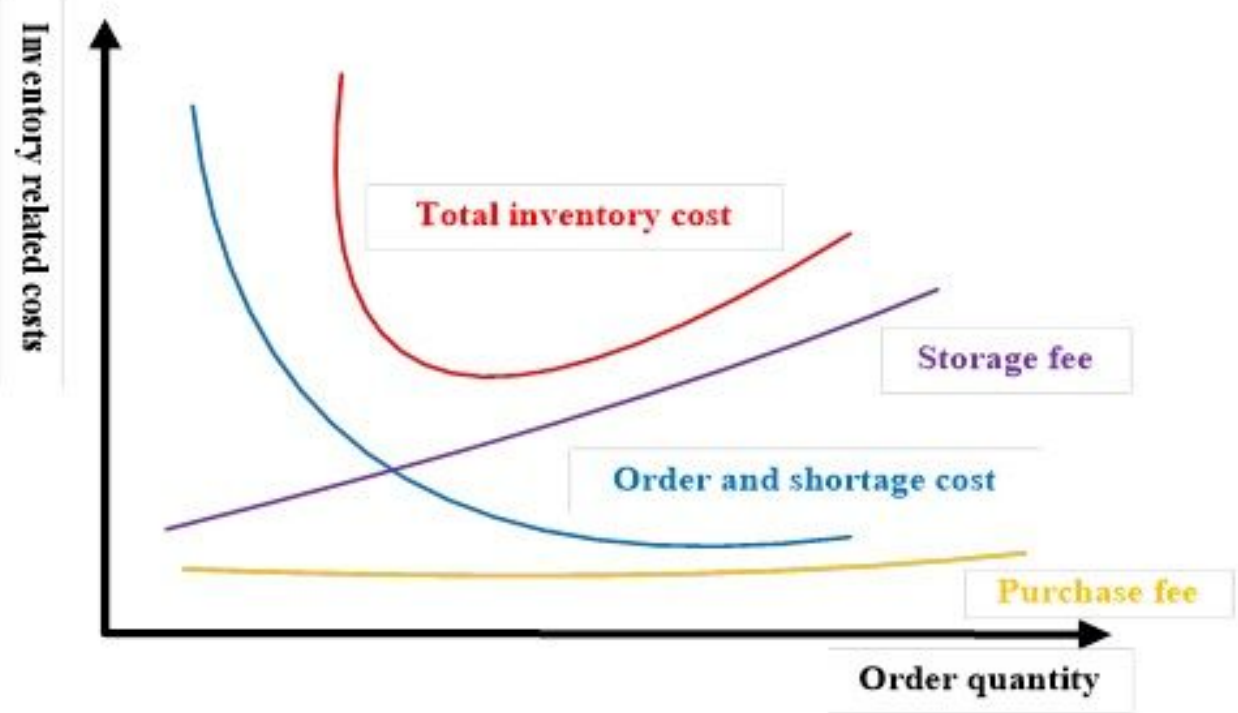

Figure 3

Analysis of system inventory cost based on VMI

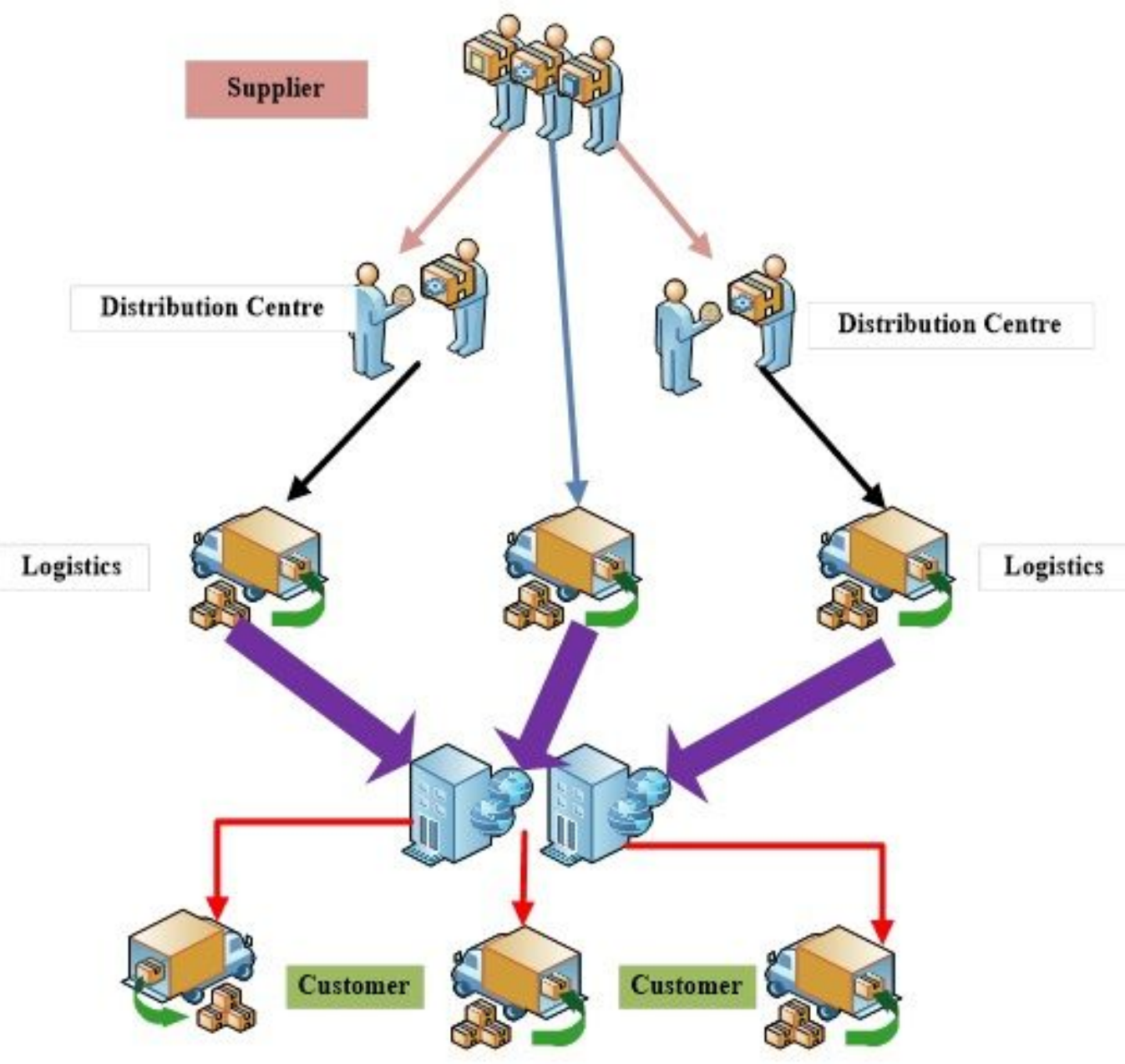


Figure 4

Traveling salesman transport map with distribution center

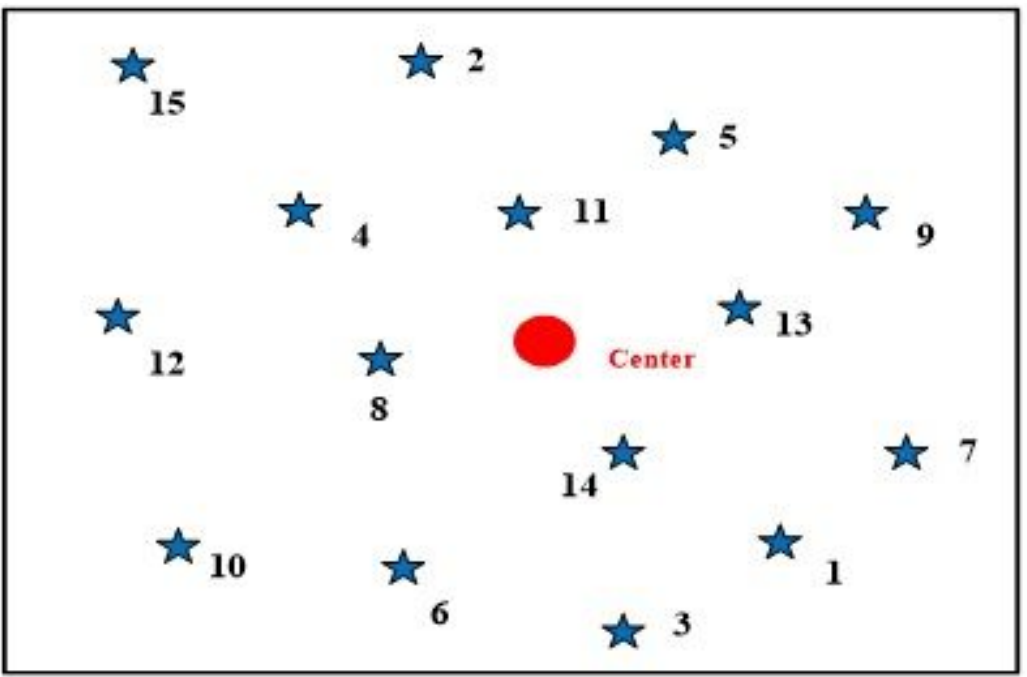

Figure 5

Coordinates of suppliers and retailers

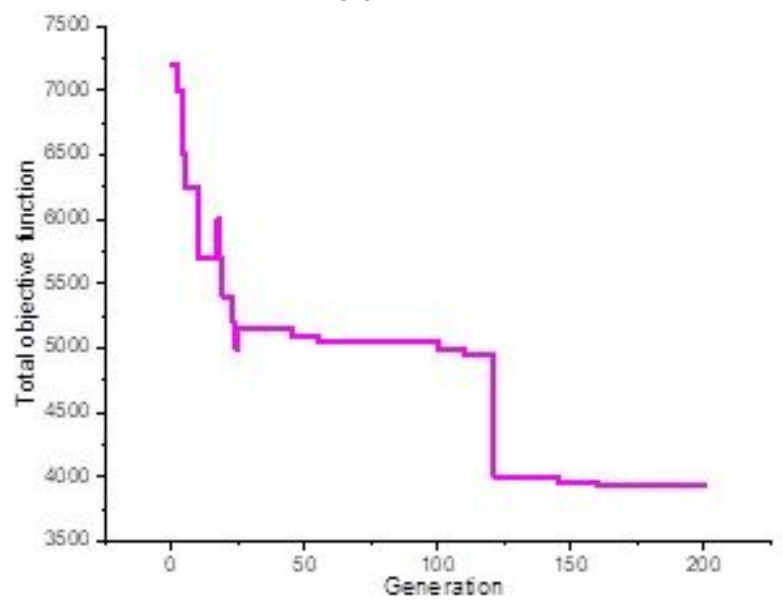

Figure 6

Iterative graph of system total objective function

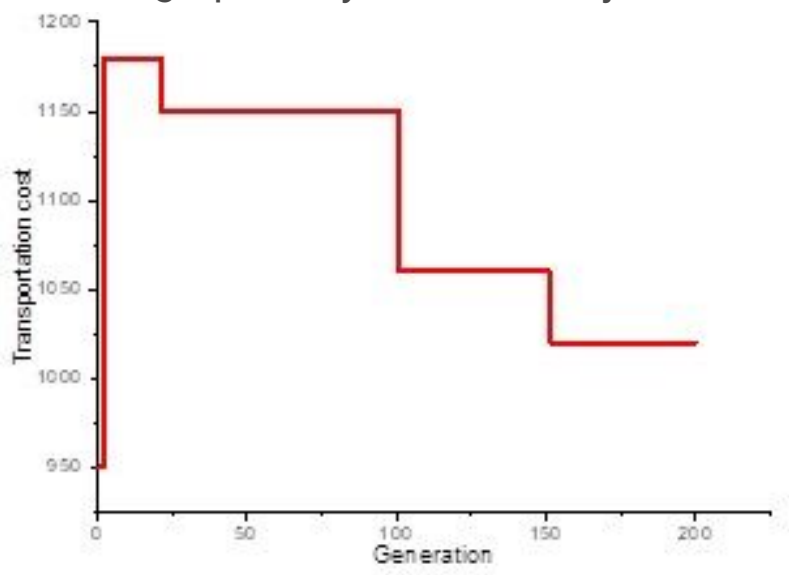


Figure 7

Transportation cost iteration chart

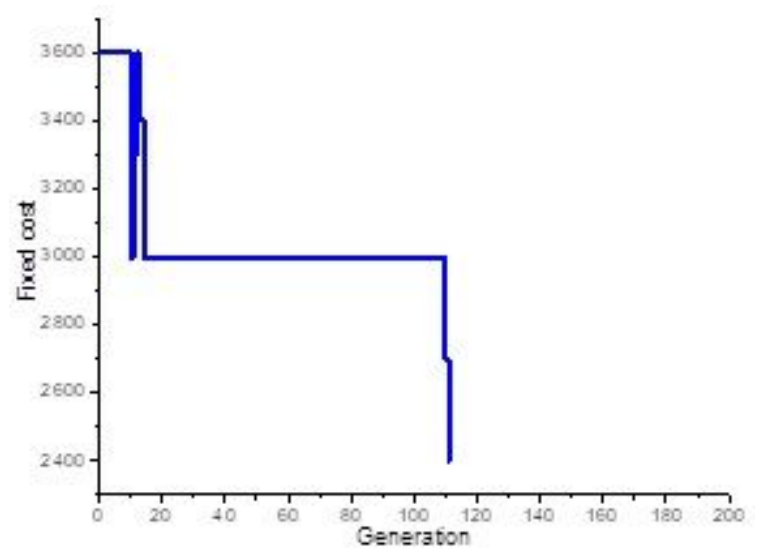

Figure 8

Fixed cost iteration chart

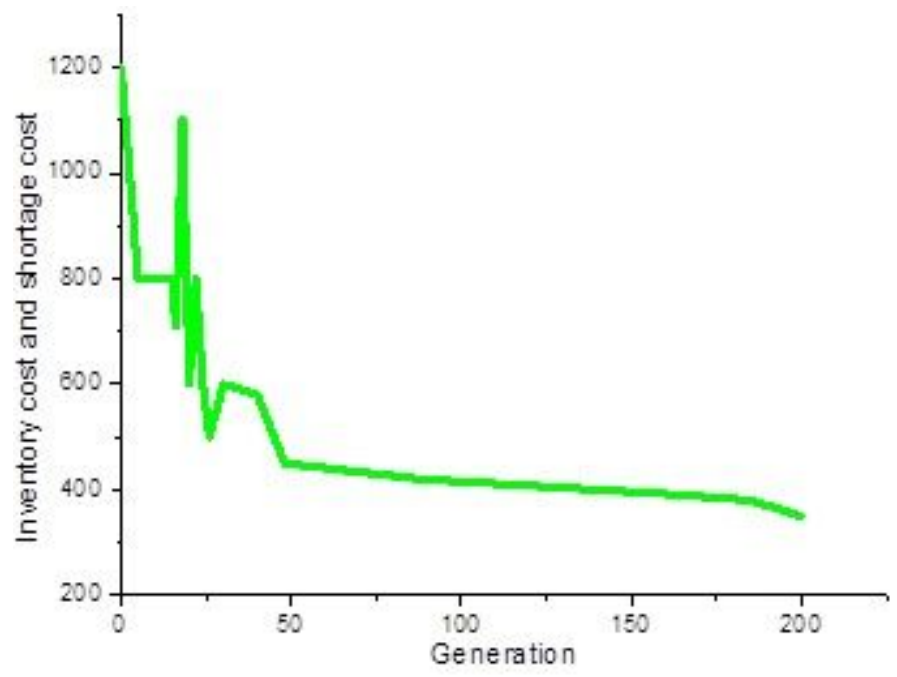

Figure 9

Iteration chart of inventory cost change 


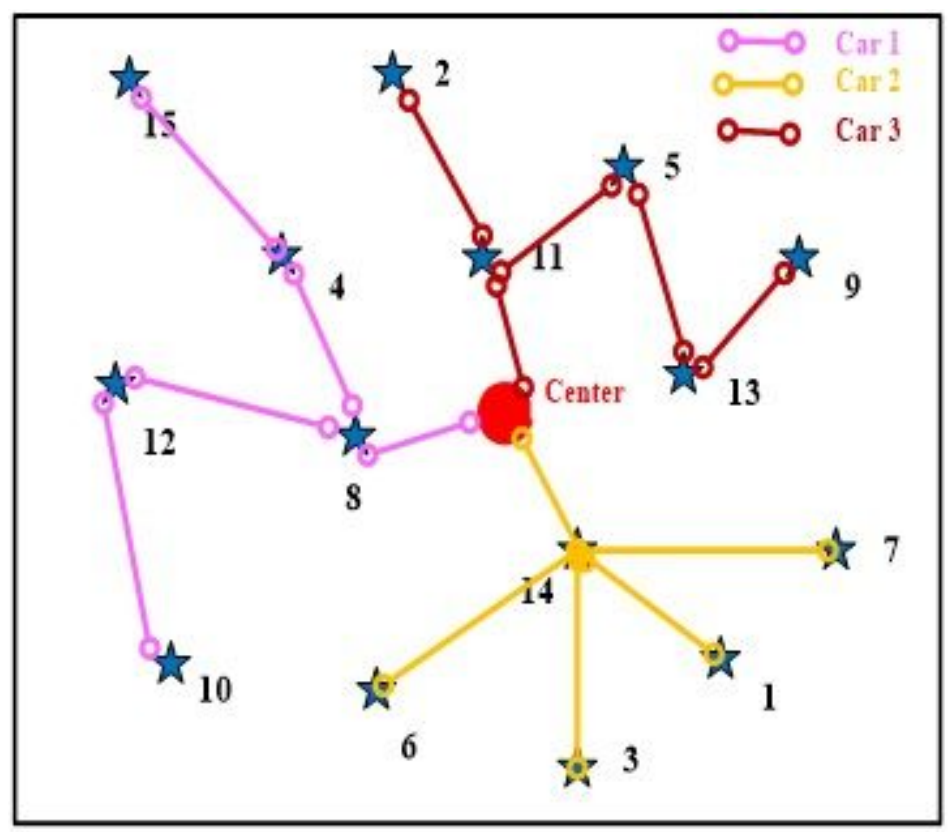

Figure 10

Vehicle route map 